\title{
Strain Hardening Behaviour in Forming of Sintered Iron-0.35\% Carbon Powder Metallurgy Preform During Cold Upsetting
}

\author{
Sumesh Narayan*, Ananthanarayanan Rajeshkannan \\ Mechanical Engineering, School of Engineering and Physics, Faculty of Science, \\ Technology \& Environment, The University of the South Pacific, \\ Laucala Campus, P.O. Box 1168, Suva, Fiji
}

Received: August 10, 2010; Revised: July 28, 2011

\begin{abstract}
A complete experimental investigation on the instantaneous strain-hardening behaviour of powder metallurgy preforms of $\mathrm{Fe}-0.35 \% \mathrm{C}$ was carried out. The strain hardening behaviour of the above-mentioned P/M sintered steel preforms with aspect ratio of 0.4 and 0.6 , respectively, under triaxial stress state condition was determined by cold upsetting under nil/no and graphite lubricant conditions. The instantaneous strain hardening value $\left(\mathrm{n}_{\mathrm{i}}\right)$, strength coefficient $\left(\mathrm{K}_{\mathrm{i}}\right)$, and the stress as a function of strain and densification were obtained and analyzed. Further, a relation is obtained from a semi-log plot of stress against relative density. This was analyzed to study the hardening behaviour due to the densification as applied stress is a function of induced strain as well as of densification in the powder metallurgy materials.
\end{abstract}

Keywords: strain hardening exponent, density hardening exponent, strength coefficient, densification

\section{Introduction}

Powder metallurgy $(\mathrm{P} / \mathrm{M})$ is a near-net shape metal forming process used to manufacture unique and innovative part to close tolerance. This technology is conducive for nearly any material that can be processed in powder form. The technology is sometimes the only manufacturing method used to produce parts with porous materials, composite materials, refractory materials and special high duty alloys. The automotive industry is the key consumer of $\mathrm{P} / \mathrm{M}$ parts due to the cost-effective nature of the process ${ }^{1-3}$. In a usual $\mathrm{P} / \mathrm{M}$ production sequence (primary processes), the powders are mixed or blended and compressed into the desired shape and then heated to cause bonding of the particles into a hard, rigid mass. A known limitation of this route is the large number of small voids left in components after sintering. The P/M parts produced by the primary processes are low in density since they contain sufficiently large amounts of pores that act as a site of stress risers and stress concentrations resulting in crack initiation and propagation when subjected to mechanical application. Hence, these parts cannot be used for heavy duty applications. A secondary deformation process such as pressing or repressing, powder extrusion, powder rolling, and infiltration is used in order to enhance the mechanical properties of sintered powder materials. Plastic deformation is the main means to improve the performance of sintered ferrous material and to obtain the final product. In general the preform produced by the conventional process will undergo a large degree of plastic deformation with enhanced levels of densification ${ }^{4-6}$. Even though the plastic deformation of powder preforms is similar to that of conventional fully dense material, additional complications arise because of substantial amount of void fractions. Therefore, deformation of a porous material is a function of both the induced stress and densification, which is not the case in fully dense material ${ }^{7,8}$.

With the application of axial tensile stress the pores will grow and densification will decrease, whereas with the application of axial compressive stress the densification enhances as the pores will collapse and ultimately close. It has been reported ${ }^{9}$ that as the density increases, the imposed stress also increases. In powder preform forging, a porous material would experience the usual strain or work hardening characteristics as well as geometrical work hardening ${ }^{10}$. However, the rate of increase in the stress value with respect to strain is greater than what would be observed in a pore free material of the same composition under identical testing conditions. This is because the continued reduction in the porosity level during upsetting increases the load bearing cross sectional area. This in turn increases the stress required for further deformation, resulting in matrix and geometric work hardening behaviour. Thus, the total strain or work hardening behaviour of the porous preform is due to the combined effects of induced densification and induced strain during cold forging ${ }^{11-13}$. Lubrication also plays an important role in the metal flow particularly in cold upsetting and affects the densification and forming limit mechanisms. A good lubrication improves the quality of products through the reduction of defects and improvement in the dimensional accuracy and surface finish ${ }^{8,14}$. Narayanasamy et al. ${ }^{15}$ investigated the instantaneous strain-hardening behavior of an aluminum-iron powder metallurgy composite with various percent of iron contents and for the various stress state conditions with two different aspect ratios. It is well known that both the strain hardening exponent and the strength coefficient are basic mechanical behaviour performance parameters of metallic materials. Therefore, the strain-hardening exponent is an important parameter reflecting a material's hardening property and its determination is of great importance ${ }^{16}$. It has been found ${ }^{10,17}$ that the initial geometry of the powder metallurgy preform has an effect on the strain hardening exponent $\left(n_{i}\right)$ and strength coefficient $\left(K_{i}\right)$.

The present investigation is aimed to experimentally study the strain hardening behaviour of powder metallurgy preforms of $\mathrm{Fe}-0.35 \% \mathrm{C}$ with the influence of aspect ratio and lubricant conditions, namely, nil/no, zinc stearate and graphite lubricant and to establish the technical relationship that exists between the characteristics of instantaneous strain hardening exponent $\left(n_{i}\right)$ with 
respect to percent fractional theoretical density and true height strain. Further, the technical relationship was established that exists between instantaneous strength coefficient $\left(K_{i}\right)$ with respect to percent fractional theoretical density and true height strain. Stress-strain and stress-densification relationship was also established for the powder metallurgy preforms deformed under nil/no, zinc stearate and graphite lubricant conditions for 0.4 and 0.6 initial aspect ratio. It is well known that for $\mathrm{P} / \mathrm{M}$ materials stress is a function of induced strain and densification, hence, a relationship was obtained from a semi-log plot of stress against relative density.

\section{Experimental Details}

\subsection{Materials and characterization}

Atomized iron powder of less than or equal to $150 \mu \mathrm{m}$ size and graphite powder of 2-3 $\mu \mathrm{m}$ size were used in the present investigation. Analysis indicated that the purity of iron was $99.7 \%$ and the rest were insoluble impurities. The characteristic (apparent density, flow rate and particle size distribution) of iron powder and $\mathrm{Fe}-0.35 \% \mathrm{C}$ blends are shown in Tables 1 and 2 .

\subsection{Blending, compaction and sintering}

A powder mix corresponding to $\mathrm{Fe}-0.35 \% \mathrm{C}$ was taken in a stainless steel pot. The powder was mixed with porcelain balls (10-15 mm diameter) with a ratio of $1: 1$ by weight. The pot containing the blended powder was subjected to the blending operation by securely tightening and then fixing it to the pot mill. The mill was operated for 20 hours to obtain a homogenous mix. Green compacts of $28 \mathrm{~mm}$ diameter with $12 \mathrm{~mm}$ of length were prepared. The powder blend was compacted on a 1.0 MN hydraulic press using a suitable die, a punch and a bottom insert in the pressure range of $430 \pm 10 \mathrm{MPa}$ to obtain an initial theoretical density of $0.84 \pm 0.01$. In order to avoid oxidation during sintering and cooling, the entire surface of the compacts was indigenously formed ceramic coated. These ceramic coated compacts were heated in the electric muffle furnace with temperature a of $1200{ }^{\circ} \mathrm{C} \pm 10^{\circ} \mathrm{C}$. At this temperature the compacts were sintered for 90 minutes followed by furnace cooling.

Table 1. Characterization of iron powder.

\begin{tabular}{cccc}
\hline Si. No. & Property & Iron & $\begin{array}{c}\text { Fe-0.35\%C } \\
\text { Blend }\end{array}$ \\
\hline 1. & Apparent Density (g/cc) & 3.38 & 3.37 \\
2. & Flow rate, (s/50 g) by Hall Flow Meter & 26.3 & 28.1 \\
3. & $\begin{array}{c}\text { Compressibility (g/cc) at pressure } \\
\text { of } 430 \pm 10 \mathrm{MPa}\end{array}$ & 6.46 & 6.26 \\
\hline
\end{tabular}

Table 2. Sieve size analysis of iron powder.

\begin{tabular}{cc}
\hline Sieve size $(\mu \mathrm{m})$ & Wt. $(\%)$ Ret. \\
\hline+150 & 10.60 \\
+125 & 24.54 \\
+100 & 15.46 \\
+75 & 19.90 \\
+63 & 11.10 \\
+45 & 8.40 \\
-45 & 10.00 \\
\hline
\end{tabular}

\subsection{Cold deformation}

Sintered and furnace cooled preforms were machined to such a dimension so as to provide height-to-diameter ratio of 0.4 and 0.6 , respectively. The initial dimensions of the cylindrical preforms were measured and recorded and used to calculate the initial density. Each specimen was compressively deformed between a flat die-set in the incremental loading step of $0.05 \mathrm{MN}$. This was done using $1 \mathrm{MN}$ capacity hydraulic press under friction conditions, which included dry, unlubricated dies called nil/no lubricant condition and lubrication consisting of graphite paste (i.e. graphite with acetone) and zinc stearate called graphite lubricant condition and zinc stearate lubricant condition, respectively. The deformation process was stopped once a visible crack appeared at the free surface. Dimensional measurements such as deformed height, deformed diameters (including bulged and contact) were carried out after every step of deformation using digital vernier caliper and the density measurements were carried out using the Archimedes principle. Experimental results were used to calculate the flow stress, true height strain, percentage theoretical density and instantaneous strength coefficient $\left(K_{i}\right.$ and $\left.C_{i}\right)$, instantaneous density hardening index $\left(m_{i}\right)$ and instantaneous strain hardening exponent $\left(n_{i}\right)$.

\section{Theoretical Analysis}

Using the measured upsetting parameters the following mathematical expressions are used to determine other upsetting parameters (stress, strain, instantaneous strain hardening and strength coefficient) for triaxial stress state. The expression for true axial stress and strain for powder metallurgy materials are as follows:

$$
\begin{aligned}
& \sigma_{z}=\frac{\text { load }}{\text { contact surface area }} \\
& \varepsilon_{z}=\ln \left(\frac{h_{o}}{h_{f}}\right)
\end{aligned}
$$

and true hoop strain is

$$
\varepsilon_{\theta}=\ln \left[\frac{2 D_{b}^{2}+D_{c}^{2}}{3 D_{o}^{2}}\right]
$$

where $h_{o}$ is the initial height of the preform; $h_{f}$ the forged height of the preform; $D_{b}$ the forged bulged diameter of the preform; $D_{c}$ the forged contact diameter of the preform; $D_{o}$ the initial diameter of the preform.

According to Narayansamy et al. ${ }^{15}$, the hoop stress $\left(\sigma_{\theta}\right)$ under triaxial stress state condition can be determined as given below:

$$
\sigma_{\theta}=\left[\frac{2 \alpha+R^{2}}{2-R^{2}+2 R^{2} \alpha}\right] \sigma_{z}
$$

where, $\alpha=\frac{d \varepsilon_{\theta}}{d \varepsilon_{z}}, d \varepsilon_{z}$ is the plastic strain increment in the axial direction and $d \varepsilon_{\theta}$ is the plastic strain increment in the hoop direction. The effective stress and the effective strain are determined by the following expressions in terms of cylindrical coordinates as explained elsewhere ${ }^{18,19}$ under triaxial stress state for axisymmetric upset forging condition $\left(\sigma_{r}=\sigma_{\theta}\right)$.

$$
\sigma_{e f f}=\left(\frac{\sigma_{z}^{2}+2 \sigma_{\theta}^{2}-R^{2}\left(\sigma_{\theta}^{2}+2 \sigma_{z} \sigma_{\theta}\right)}{2 R^{2}-1}\right)^{0.5}
$$




$$
\varepsilon_{\text {eff }}=\left[\left(\frac{2}{3(2+R)}\right)\left[\left(\varepsilon_{z}-\varepsilon_{\theta}\right)^{2}+\left(\varepsilon_{\theta}-\varepsilon_{z}\right)^{2}\right]+\left(\frac{\left(\varepsilon_{z}+2 \varepsilon_{\theta}\right)^{2}}{3}\right)\left[1-R^{2}\right]\right]^{0.5}
$$

Equations 5 and 6 are utilized to determine the strain hardening parameters as explained here. An attempt was made to use plastic flow (Ludwik) equation $\sigma=K \varepsilon^{n}$, with little modification for P/M preforms to determine the instantaneous strength $\left(K_{i}\right)$ and instantaneous strain hardening $\left(n_{i}\right)$, where $\sigma$ is true effcetive stress; $\varepsilon$ is true effective strain; $K$ is strength co-efficient and $n$ is strain hardening exponent. The theoretical description follows:

Assuming consecutive effective load on the preform were specified as $1,2,3, \ldots,(m-1)$ and $m$. Now the plastic flow equation can be written as follows:

$$
\begin{aligned}
& \sigma_{m}=K \varepsilon_{m}^{n} \\
& \sigma_{m-1}=K \varepsilon_{m-1}^{n}
\end{aligned}
$$

Subtracting Equations 7 and 8, the following expression can be obtained

$$
\sigma_{m}-\sigma_{m-1}=K\left(\varepsilon_{m}^{n}-\varepsilon_{m-1}^{n}\right)
$$

The Equation 9 can further deduce into

$$
K_{i}=\frac{\sigma_{m}-\sigma_{m-1}}{\varepsilon_{m}^{n}-\varepsilon_{m-1}^{n}}
$$

Now, dividing the Equation 7 by Equation 8, the following expression is obtained

$$
\frac{\sigma_{m}}{\sigma_{m-1}}=\frac{\varepsilon_{m}^{n}}{\varepsilon_{m-1}^{n}}=\left(\frac{\varepsilon_{m}}{\varepsilon_{m-1}}\right)^{n}
$$

Taking natural logarithm on both sides of Equation 11, it follows,

$$
\ln \left(\frac{\sigma_{m}}{\sigma_{m-1}}\right)=n \ln \left(\frac{\varepsilon_{m}}{\varepsilon_{m-1}}\right)
$$

Equation 12 can further simplify into

$$
n_{i}=\frac{\ln \left(\frac{\sigma_{m}}{\sigma_{m-1}}\right)}{\ln \left(\frac{\varepsilon_{m}}{\varepsilon_{m-1}}\right)}
$$

Equations 10 and 13 can be utilized for determining the instantaneous strength coefficient and instantaneous strain hardening exponent from the experimental data corresponding to stress and strain.

Further, from the semi-log plot of stress against relative density the following relationship can be deduced. The linear relationship can be expressed as

$$
\log \sigma=m R+\log C
$$

where $R$ is the relative density, $m$ is the density hardening index and $C$ is the density strength coefficient. Equation 14 can be reduced to it general form as

$$
\sigma=C e^{(m R)}
$$

Assuming consecutive effective load on the preform were specified as 1,2,3,.., (i-1) and $i$. Now Equation 15 can be written as

$$
\begin{gathered}
\sigma_{i}=C e^{\left(m R_{i}\right)} \\
\sigma_{i-1}=C e^{\left(m R_{i-1}\right)}
\end{gathered}
$$

Dividing Equation 1 by Equation 2 gives

$$
\frac{\sigma_{i}}{\sigma_{i-1}}=\frac{C e^{\left(m R_{i}\right)}}{C e^{\left(m R_{i-1}\right)}}
$$

Taking natural logarithm on both sides of Equation 18, it follows,

$$
\ln \left(\frac{\sigma_{i}}{\sigma_{i-1}}\right)=m\left(R_{i}-R_{i-1}\right)
$$

Equation 19 can further simplify into

$$
m_{i}=\frac{\ln \left(\frac{\sigma_{i}}{\sigma_{i-1}}\right)}{R_{i}-R_{i-1}}
$$

Using Equation 20, the instantaneous density hardening index $\left(m_{i}\right)$ can be determined. Further, subtracting Equation 16 from Equation 17 the following expression can be obtained:

$$
\sigma_{i}-\sigma_{i-1}=C\left(e^{m R_{i}}-e^{m R_{i-1}}\right)
$$

Equation 21 can further be rearranged as:

$$
C_{i}=\frac{\sigma_{i}-\sigma_{i-1}}{e^{m R_{i}}-e^{m R_{i-1}}}
$$

From the above Equation 22, the instantaneous density strength coefficient $\left(C_{i}\right)$ can be determined.

\section{Results and Discussion}

Cold working is one of the methods to promote strength in metals; in this case strain induced will be the prominent factor for a fully dense material. The same is true for $\mathrm{P} / \mathrm{M}$ material too, however the additional factor that governs its behaviour is pore closure or density attained. It is well established ${ }^{8}$ that attaining full density along with the mode by which it is attained is a significant phenomenon that governs the strength of P/M material. Thus, Figure 1 shows the relationship between axial stress and relative density for $\mathrm{Fe}-0.35 \% \mathrm{C}$ $\mathrm{P} / \mathrm{M}$ preform for two different aspect ratio cold deformed under three different frictional conditions, namely, nil/no, graphite and zinc stearate lubricant condition. The characteristics nature of the curves is similar since as the densification increases flow stress also increases continuously. Due to the continual application of the applied stress the pores present in the P/M material collapse and close enhancing the densification and increasing the strength of the $\mathrm{P} / \mathrm{M}$ material by cold deformation. To further deform the P/M preforms require additional load, hence, increasing the applied load as the deformation and density increases to near theoretical density. It can be seen that the axial stress increases rapidly during the initial and final stages of deformation. The initial application of load is not sufficient to continuously deform the preform and the applied load increases the compressive stresses amongst the particles of the preform. During the intermediate stage the stress increases gradually as deformation progresses in both axial and lateral directions. However, a sharp increase in stress values for low densification during the final stage is 
due to the strain hardening of the material. Further, it is observed for any value of percent fractional theoretical density, the lower aspect ratio preform deformed under nil/no lubricant condition experience higher stress values compared to higher aspect ratio preform. Further,

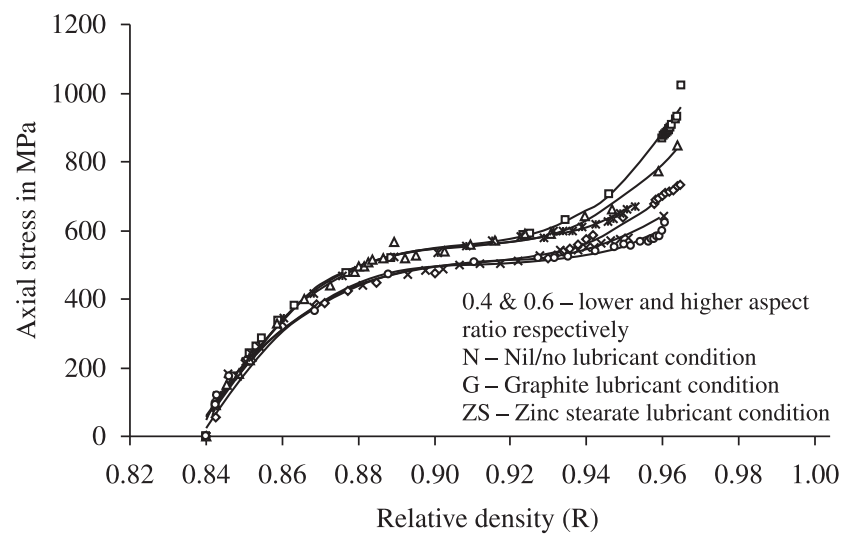

$\square \mathrm{N} 0.4 \diamond \mathrm{N} 0.6 \quad \Delta \mathrm{G} 0.4 \quad \times \mathrm{G} 0.6 \quad * \mathrm{ZS} 0.4 \quad \circ \mathrm{ZS} 0.6$

Figure 1. Variation of axial stress and relative density for cold deformed $\mathrm{Fe}-0.35 \% \mathrm{C}$ preform.

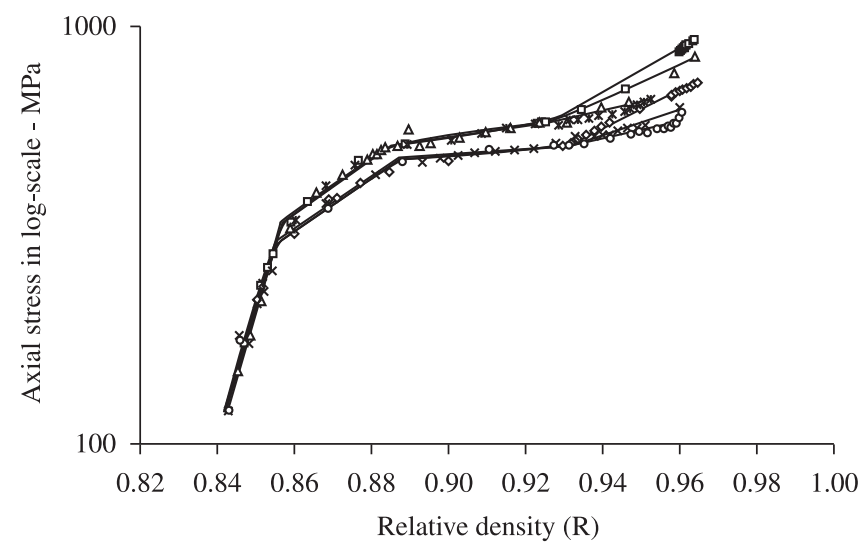

$\square \mathrm{N} 0.4 \diamond \mathrm{N} 0.6 \quad \Delta \mathrm{G} 0.4 \quad \times$ G $0.6 \quad *$ ZS $0.4 \quad$ ○ ZS 0.6

Figure 2. Variation of axial stress in log-scale and relative density for cold deformed $\mathrm{Fe}-0.35 \% \mathrm{C}$ perform. the effect of frictional constraints is only evident during the final stages of deformation and it can also be noted that graphite lubricant provides better densification characteristics in comparison to zinc stearate lubricant condition.

Powder metallurgy preforms when subjected to applied load during cold upsetting deform as well as increase in density and hence, does not conform to volume constancy principle unlike in the fully dense material. Therefore, stress and strength of the P/M materials depends on both strain and densification. Figure 2 shows the relationship between axial stress in log-scale and relative density for $\mathrm{Fe}-0.35 \% \mathrm{C}$ P/M preform for two different aspect ratio cold deformed under three different frictional conditions, namely, nil/no, graphite and zinc stearate lubricant condition. The relationship between true stress and relative density follows a relationship which can be expressed as $\sigma=C e^{(m R)}$ where $C$ referred to as density strength coefficient and $m$ referred to as density hardening exponent and these two parameters can be utilized to understand the stress densification phenomenon in enhancing the strength of the P/M material via cold deformation. The characteristics nature of the curves shown in Figure 2 is similar and follows four different mechanisms. Table 3 shows the values of $m_{i}$ and $C_{i}$ obtained from Figure 2 for two different aspect ratios and three different frictional constraints. A significant high and low values of $m_{i}$ and $C_{i}$, respectively, during mechanism one can be neglected for all practical purposes as initial application of applied load are not

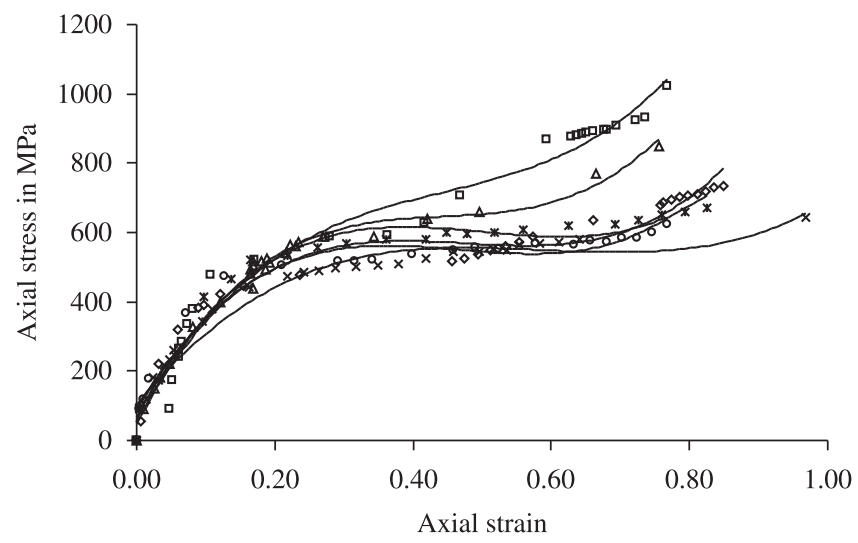

$\square \mathrm{N} 0.4 \diamond \mathrm{N} 0.6 \Delta \mathrm{G} 0.4 \times \mathrm{G} 0.6 \quad * \mathrm{ZS} 0.4 \quad \mathrm{ZS} 0.6$

Figure 3. Variation of axial stress and axial strain for cold deformed $\mathrm{Fe}-0.35 \% \mathrm{C}$ preform

Table 3. Values of $m_{i}$ and $C_{i}$ for $\mathrm{Fe}-0.35 \% \mathrm{C}$.

\begin{tabular}{|c|c|c|c|c|c|c|c|}
\hline \multirow{3}{*}{$\begin{array}{l}\text { Aspect } \\
\text { ratio }\end{array}$} & \multirow{3}{*}{$\begin{array}{l}\text { Mechanism } \\
\text { of density } \\
\text { hardening }\end{array}$} & \multicolumn{6}{|c|}{ Frictional constraints } \\
\hline & & \multicolumn{2}{|c|}{ Nil/no lubricant } & \multicolumn{2}{|c|}{ Graphite lubricant } & \multicolumn{2}{|c|}{ Zinc stearate } \\
\hline & & $m_{i}$ & $C_{i}$ & $m_{i}$ & $C_{i}$ & $m_{i}$ & $C_{i}$ \\
\hline \multirow{4}{*}{0.4} & 1 & 28.57 & $6.18 \times 10^{-9}$ & 28.57 & $6.18 \times 10^{-9}$ & 28.57 & $6.18 \times 10^{-9}$ \\
\hline & 2 & 6.36 & 1.80 & 6.36 & 1.80 & 6.36 & 1.80 \\
\hline & 3 & 1.50 & 142.86 & 1.50 & 142.86 & 1.50 & 142.86 \\
\hline & 4 & 5.11 & 5.99 & 3.47 & 25.82 & 1.44 & 159.20 \\
\hline \multirow{4}{*}{0.6} & 1 & 28.57 & $6.18 \times 10^{-9}$ & 28.57 & $6.18 \times 10^{-9}$ & 28.57 & $6.18 \times 10^{-9}$ \\
\hline & 2 & 5.96 & 2.11 & 5.96 & 2.11 & 5.96 & 2.11 \\
\hline & 3 & 0.62 & 286.46 & 0.62 & 286.46 & 0.62 & 286.46 \\
\hline & 4 & 4.60 & 7.87 & 3.28 & 26.02 & 2.27 & 65.21 \\
\hline
\end{tabular}




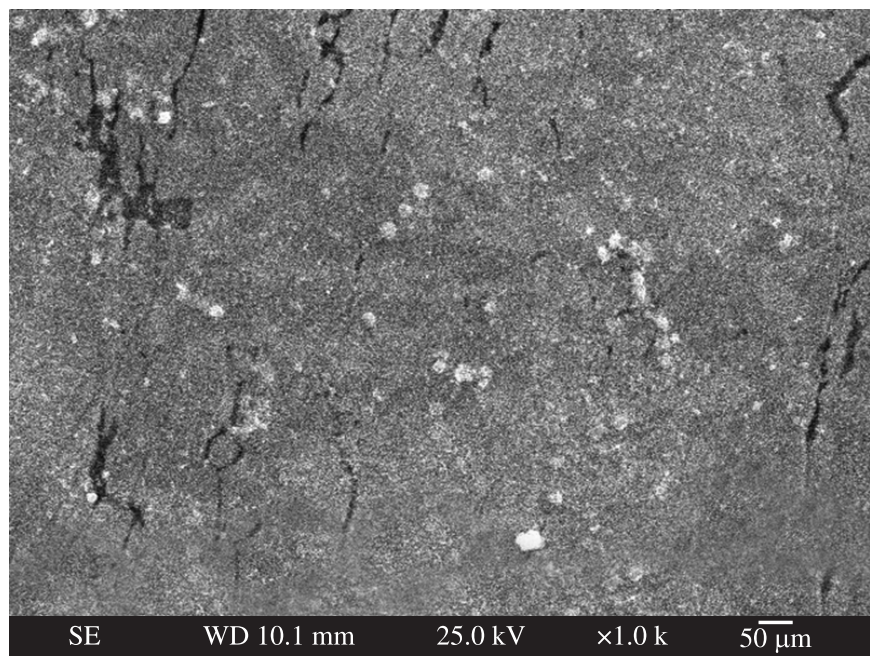

(a)

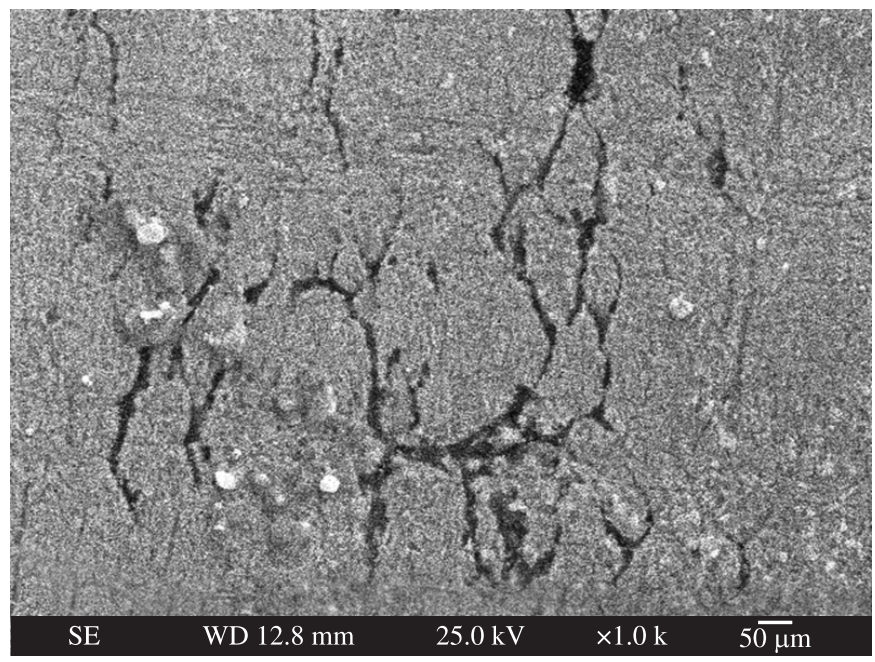

(b)

Figure 4. a, b) Microstructure view at diametric extreme of the preform deformed under nil/no and graphite employed lubricant respectively.

sufficient to deform the P/M preform and during the initial stages of deformation the P/M preform was able to resist the applied load until it exceeded the initial yield stress of the P/M material. It can be seen that an inverse relationship exists between the density hardening exponent $\left(m_{i}\right)$ and density strength coefficient $\left(C_{i}\right)$ (as $m_{i}$ increases $C_{i}$ decreases and vise versa). Increasing the frictional constraints and reducing the aspect ratio increases the density hardening exponent $\left(m_{i}\right)$, however, the density strength coefficient $\left(C_{i}\right)$ reduces.

Figure 3 shows the relationship between axial stress and axial strain for $\mathrm{Fe}-0.35 \% \mathrm{C}$ P/M preform for two different aspect ratio cold deformed under three different frictional conditions, namely, nil/no, graphite and zinc stearate lubricant condition. For any given true height strain the axial stress increases with increasing frictional constraints and reducing aspect ratio. The lateral deformation is more pronounced in the graphite and zinc stearate employed preforms. From Figure 4 it can be seen that the pores (black color) are more elongated for graphite employed lubricant when compared to nil/ no lubricant condition. This is the reason for enhanced axial stress values for lower aspect ratio preform deformed under nil/no lubricant condition. It can also be noted that graphite lubricant provides better deformation characteristics in comparison to zinc stearate lubricant condition.

Figures 5 and 6 show the relationship between strain hardening exponent against relative density and axial strain, respectively, for $\mathrm{Fe}-0.35 \% \mathrm{C} \mathrm{P} / \mathrm{M}$ preform for two different aspect ratio cold deformed under two different frictional conditions, namely, nil/no and graphite lubricant condition. The characteristics nature of the curves follow similar trend, a sudden increase in strain hardening exponent with little densification and deformation followed by a sudden decrease in the strain hardening exponent values and then it follows a gradual decrease for 0.87 to 0.93 relative density and for 0.09 to 0.4 true height strain, respectively. Further, up to 0.955 relative density and 0.78 axial strain, a gradual increase in strain hardening exponent is seen. After 0.955 relative density and 0.78 true height strain a mild to heavy fluctuations in strain hardening exponent values are observed. This behaviour is true irrespective of lubricant employed. During the initial stages of deformation high axial stress values are obtained (Figures 1 and 3) and is the reason for high strain hardening exponent which in no means increases the strength of the material and can be neglected. The larger pores present in large amounts

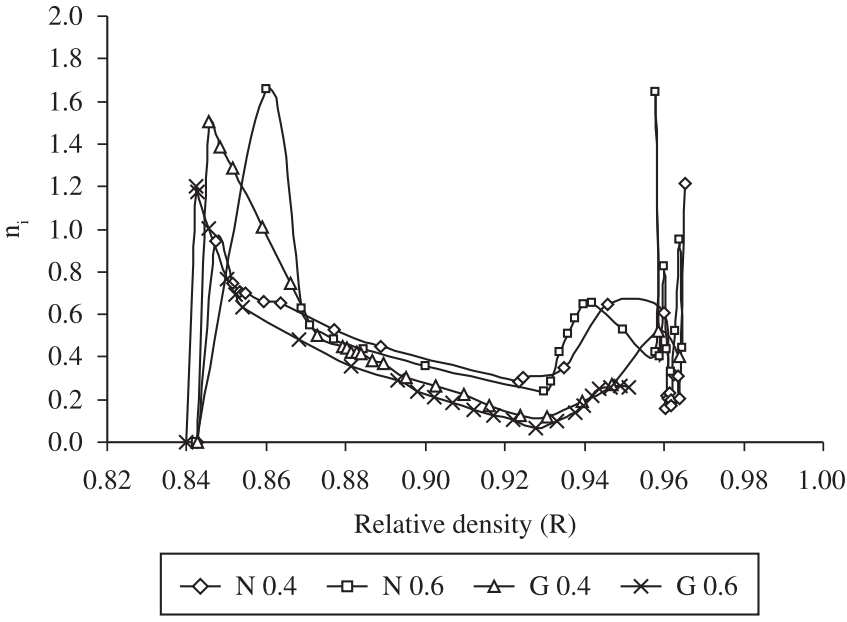

Figure 5. Variation of strain hardening exponent and relative density for cold deformed $\mathrm{Fe}-0.35 \% \mathrm{C}$ preform.

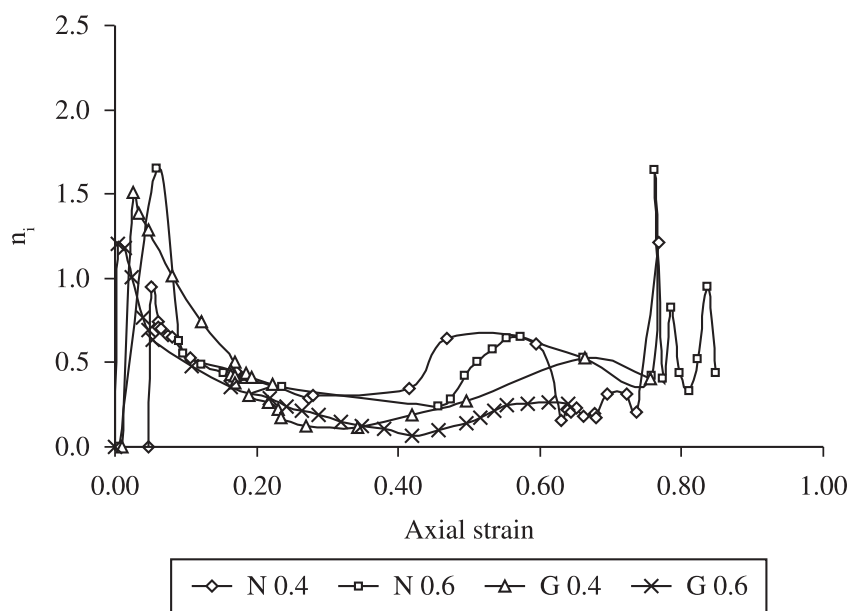

Figure 6. Variation of strain hardening exponent and axial strain for cold deformed $\mathrm{Fe}-0.35 \% \mathrm{C}$ preform. 
initially are elongated (Figure 4) due to the application of applied load. This is the reason for a decrease in strain hardening exponent and after the effective closure of pores the strain hardening exponent increases. During the final stages of deformation the P/M material approaches near theoretical density with 4 to $5 \%$ porosity left, which are difficult to close. The $\mathrm{P} / \mathrm{M}$ preforms are highly strain hardened at this point, hence, to further close the remaining pores requires high applied stress which in turn significantly increases the strain hardening values. When these remaining pores collapse it significantly reduces the strain hardening values. This causes fluctuations in the strain hardening values in the final stages of deformation. Further, from Figures 5 and 6, it is noticed that the strain hardening values are enhanced for nil/no lubricant condition and lower aspect ratio preform in comparison to graphite lubricant condition and higher aspect ratio preform, respectively, and the fluctuations of strain hardening values are severe in the case of nil/no lubricant condition. It can be concluded that strain hardening is promoted in the P/M preform by increasing the frictional constraints and reducing the aspect ratio.

Figures 7 and 8 shows the relationship between strength coefficient against relative density and axial strain, respectively, for

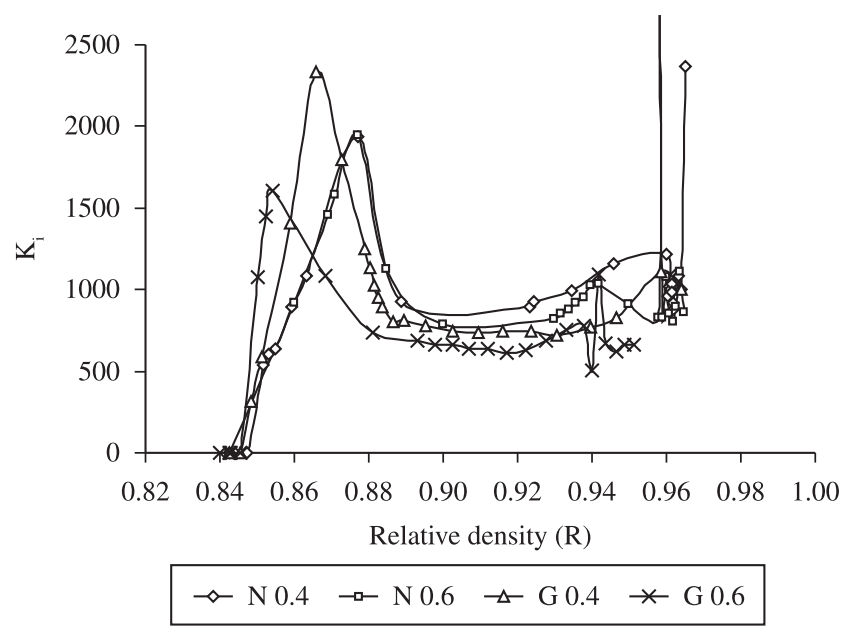

Figure 7. Variation of strength coefficient and relative density for cold deformed $\mathrm{Fe}-0.35 \% \mathrm{C}$ preform.

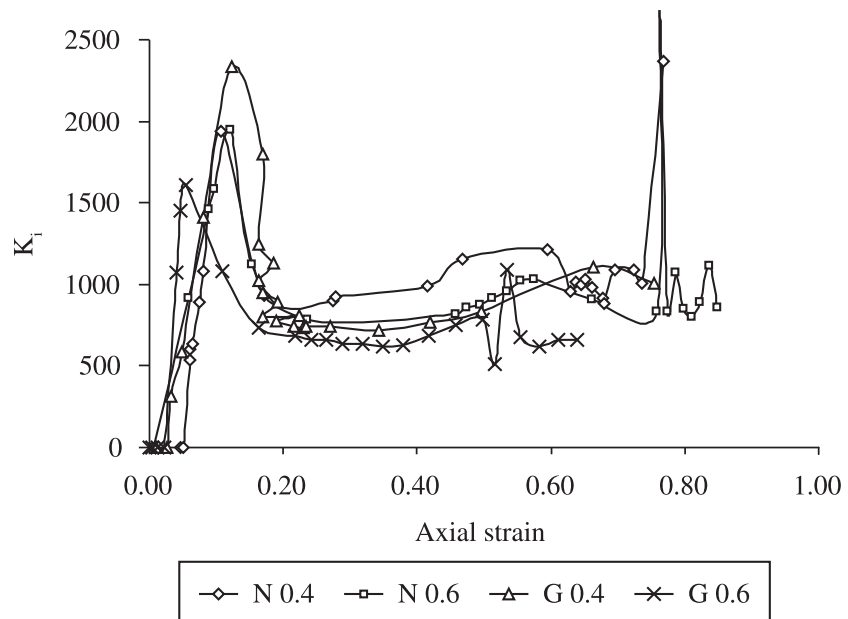

Figure 8. Variation of strength coefficient and axial strain for cold deformed $\mathrm{Fe}-0.35 \% \mathrm{C}$ preform.
Fe- $0.35 \% \mathrm{C} \mathrm{P} / \mathrm{M}$ preform for two different aspect ratio cold deformed under two different frictional conditions, namely, nil/no and graphite lubricant condition. The curves plotted in Figures 7 and 8 show that the strength coefficient increases rapidly at low values of densification and strain rate followed by a decrease in the strength coefficient values. Thereafter from 0.89 relative density to 0.96 relative density and 0.18 axial strain to 0.78 axial strain, respectively, the strength coefficient slowly increases at a steady rate and after 0.96 relative density and 0.78 axial strain a fluctuation in the strength coefficient values are noticed. The fluctuations in the strength values are severe for nil/no lubricant condition in comparison to graphite employed lubricant. The slope of the curve during the intermediate stage is higher for nil/no lubricant condition and lower aspect ratio preform compared to graphite employed lubricant condition and higher aspect ratio preform. It can be said that increasing the frictional constraints and reducing aspect ratio enhances the strength coefficient.

\section{Conclusions}

The major conclusions have been drawn from the present investigations that are as follows:

- Axial stresses increased with the enhancement of deformation and densification; followed three different mechanisms of deformation irrespective of frictional constraints and aspect ratio. Initial and final stage exhibits high resistance to deformation. However, during the intermediate stage stresses rise at a steady rate due to extended deformation and densification;

- The strain hardening and strength coefficient in the P/M preform were improved when the frictional constraints were increased and aspect ratio was reduced;

- Faster and effective closure of pores is found to be higher when preforms are deformed under nil/no lubricant condition;

- Two new parameters namely density hardening exponent $\left(m_{i}\right)$ and density strength coefficient $\left(C_{i}\right)$ are introduced to study hardening behaviour in $\mathrm{P} / \mathrm{M}$ material by densification.

\section{References}

1. Lindskog P. Economy in car-making - powder metallurgy, Global Automotive Manufacturing and Technology, Technology \& Services. London: Business Briefing; 2003.

2. Ryuichiro G. Powder metallurgy growth in the automotive market, Global Automotive Manufacturing and Technology, Materials. London: Business Briefing; 2003.

3. Rosochowski A, Beltrando L and Navarro S. Modeling of density and dimensional changes in re-pressing/sizing of sintered components. Journal of Materials Processing Technology. 1998; 80:188-194. http://dx.doi.org/10.1016/S0924-0136(98)00184-8

4. Hua L, Qin X, Mao H and Zhao Y. Plastic deformation and yield criterion for compressible sintered powder materials. Journal of Materials Processing Technology. 2006; 180:174-178. http://dx.doi.org/10.1016/j. jmatprotec.2006.06.001

5. Liu Y, Chen LF, Tang HP, Liu CT, Liu B and Huang BY. Design of powder metallurgy titanium alloys and composites. Material Science Engineering A. 2006; 418:25-35. http://dx.doi.org/10.1016/j.msea.2005.10.057

6. Kandavel TK, Chandramouli R and Ravichandran M. Experimental study on the plastic deformation and densification characteristics of some sintered and heat treated low alloy powder metallurgy steels. Materials and Design. 2010; 31:485-492. http://dx.doi.org/10.1016/j. matdes.2009.06.048

7. Jha AK and Kumar S. Forging of metal powder preforms. International Journal of Machine Tool Design and Research. 1983; 23:201. http://dx.doi.org/10.1016/0020-7357(83)90039-2 
8. Rajeshkannan A and Narayan S. Strain hardening behaviour in sintered $\mathrm{Fe}-0.8 \% \mathrm{C}-1.0 \% \mathrm{Si}-0.8 \% \mathrm{Cu}$ powder metallurgy preform during cold upsetting. Journal of Engineering Manufacture. 2009; 223:1567-1574. http://dx.doi.org/10.1243/09544054JEM1587

9. Rajeshkannan A, Pandey KS, Shanmugam S and Narayanasamy R Sintered Fe-0.8\%C-1.0\% Si-0.4\% Cu P/M preform behaviour during cold upsetting. Journal of Iron and Steel Research, International. 2008; 15:81-8. http://dx.doi.org/10.1016/S1006-706X(08)60254-X

10. Narayanasamy R and Pandey KS. Some aspects of work hardening in sintered aluminium - iron composite preforms during cold axial forming. Journal of Materials Processing Technology. 1998; 84:136-142. http://dx.doi.org/10.1016/S0924-0136(98)00088-0

11. Kahlow KJ. Void behaviour as influenced by pressure and plastic deformation. Institute for Metal Forming Report, Lehigh University; 1971.

12. Taha MA, El-Mahallawy NA and El-Sabbagh AM. Some experimental data on workability of aluminium-particulate-reinforced metal matrix composites. Journal of Materials Processing Technology. 2008; 202:380-385. http://dx.doi.org/10.1016/j.jmatprotec.2007.07.047

13. Zhang XQ, Peng YH, Li MQ, Wu SC and Ruan XY. Study of workability limits of porous materials under different upsetting conditions by compressible rigid plastic finite element method. Journal of Materials Engineering and Performance. 2000; 9:164-169. http://dx.doi. org/10.1361/105994900770346114
14. Simchi A. Effects of lubrication procedure on the consolidation, sintering and microstructural features of powder compacts. Materials and Design. 2003; 24:585-594. http://dx.doi.org/10.1016/S0261-3069(03)00155-9

15. Narayanasamy R, Ramesh T and Pandey KS. An investigation on instantaneous strain hardening behaviour in three dimensions of aluminiumiron composites during cold upsetting. Material Science Engineering A. 2005; 391:418-426. http://dx.doi.org/10.1016/j.msea.2004.09.018

16. Ebrahimi R and Pardis N. Determination of strain-hardening exponent using double compression test. Material Science Engineering A. 2008; 497:505-511.

17. Pandey KS. Some investigations on the cold deformation behaviour of sintered aluminium-4\% copper alloy powder preforms. International Journal of Powder Metallurgy Science and Technology. 1991; 2:35-44.

18. Doraivelu SM, Gegel HL, Gunasekera JS, Malas JC, Morgan JT and Thomas Junior JF. New yield function for compressible P/M materials. International Journal of Mechanical Science. 1984; 26:527-535. http://dx.doi.org/10.1016/0020-7403(84)90006-7

19. Narayanasamy R, Anandakrishnan V and Pandey KS. Effect of geometric work-hardening and matrix work-hardening on workability and densification of aluminium-3.5\% alumina composite during cold upsetting. Materials and Design. 2008; 29:1582-1599. http://dx.doi. org/10.1016/j.matdes.2007.11.006

Appendix 1. Notation.

\begin{tabular}{llll}
\hline$C$ & Carbon & $\varepsilon_{\text {eff }}$ & Effective strain \\
$F e$ & Iron & $K$ & Strength co-efficient \\
$\varepsilon_{\theta}$ & True hoop strain & $K_{i}$ & Instantaneous strength co-efficient \\
$\varepsilon_{z}$ & True axial strain & $n$ & Strain hardening exponent \\
$R$ & Fractional theoretical density & $n_{i}$ & Instantaneous strain hardening exponent \\
$\sigma_{z}$ & Axial stress & $C$ & Density strength coefficient \\
$\sigma_{\theta}$ & Hoop stress & $C_{i}$ & Instantaneous density strength coefficient \\
$\sigma_{r}$ & Radial stress & $m$ & Density hardening exponent \\
$\sigma_{e f f}$ & Effective stress & $m_{i}$ & Instantaneous density hardening exponent \\
\hline
\end{tabular}

